\title{
Rehabitar el tiempo: el arte de darle voz a través de la máquina en Yucef Merhi'
}

\section{Re-inhabiting time: the art of granting it voice through the machine in Yucef Merhi}

Daniela Díaz Larralde ${ }^{2}$

Universidad Simón Bolívar, Caracas, Venezuela

danydiazlarralde@gmail.com

\section{RESUMEN}

La intención es analizar en este trabajo, a partir de distintas concepciones del tiempo y de nuestro tiempo como momento histórico —-Heidegger, Bergson, Lyotard-, El reloj poético, obra plástica con la que Yucef Merhi inaugura, en 1997, junto con otras dos - Poliverso andróctono y Abstractombola - y un poemario, su trayectoria como artista/ poeta/hacker. Se trata de un reloj que es capaz de generar 86400 poemas al día, uno por cada segundo, y que el artista propone como una máquina que convierte el tiempo en poesía. Este singular reloj, construido y programado por Merhi, revelará que, paralela a la duración que marca la máquina en términos de "cuánto» y de "cuándo», medida que responde a la intención racional de cuantificar y controlar el tiempo y la realidad, discurre otra que escapa al número porque no es cantidad sino cualidad, porque no es homogénea sino heterogénea, porque no es razón sino emoción. A partir de esta obra será posible entonces no solo medir el tiempo, igual para todos, sino percibirlo como experiencia individual.

\footnotetext{
1 Este artículo surge de una ponencia presentada en el I Congreso de Literatura y Arte (Universidad Metropolitana de Caracas, octubre de 2013) y después, ampliada, en la IV Semana Latinoamericana y Caribeña de la Universidad Simón Bolívar (USB) (noviembre de 2013).

2 Es licenciada en Letras de la Universidad Central de Venezuela. Cursó en Madrid un posgrado en Estudios Avanzados de Edición y un estudio intensivo de Diagramación en Editrain SL. En la Universidad Simón Bolívar se ha desempeñado como asistente editorial de la Revista Estudios, del Departamento de Lengua y Literatura (2008), como correctora externa de la Editorial Equinoccio (2009-2013) y como coordinadora editorial de la revista Mundo Nuevo del Instituto de Altos Estudios de América Latina (IAEAL-USB). En 2013 obtuvo el título de magíster en Literatura Latinoamericana de la Universidad Simón Bolívar. Desde 2009 es docente del Departamento de Lengua y Literatura de la misma universidad.
} 


\section{PALABRAS CLAVE}

El reloj poético, Yucef Merhi, tiempo, lenguaje, poesía

\section{ABSTRACT}

Through this study, the aim is to analyze, stemming from contrasting concepts of time and of our time as a historical moment —Heidegger, Bergson, Lyotard-, El reloj poético (The Poetic Clock), a work of art that inaugurates in 1997, together with two other works -Poliverso Andróctono and Abstractombola - and a book of poems, Yucef Merhi's personal path as an artist/poet/hacker. This is a clock capable of generating 86.400 poems a day, one for each second, which the artist proposes as a machine that converts time into poetry. This highly original clock, built and programmed by Merhi, will reveal that, in parallel fashion to what the machine indicates in terms of «how much» and «when», a measurement that answers the rational intention of quantifying and controlling time and reality, there exists another one that escapes ciphers due to the fact that is not quantity, but rather quality, because it is not homogenous, but rather heterogeneous, because it is not reason, but rather emotion. Through this work it will be possible no just to measure time, a time equal to all, but also to perceive it as an individual experience.

\section{KEYWORDS}

The poetic clock, Yucef Merhi, time, language, poetry

Tu materia es el tiempo, el incesante Tiempo. Eres cada solitario instante.

Borges. «El ápice» («La cifra»)

Yucef Merhi es un artista plástico, poeta y hacker venezolano que ha orientado su quehacer artístico hacia la creación de obras que, por una parte, invitan o, mejor dicho, convocan al espectador, de diversas maneras, a reflexionar acerca de temas fundamentales relacionados con la tecnología, el arte, la poesía, el lenguaje y la cultura; y, por otra, se constituyen como importantes registros de la transición que en estos tiempos nos ha tocado vivir, experimentar, no solo como sociedad, sino como especie humana, resultado de la influencia del vertiginoso desarrollo de lo tecnológico, acentuado a partir de la aparición de la computadora y de la red de internet. Una de esas obras, que es la que interesa abordar en esta ocasión, es El reloj poético, expuesta por primera vez en 1997, en el III 
Salón Pirelli, junto a otra, también de su autoría, titulada Abstractombola. El reloj poético se propone como una máquina, construida y programada por el artista, que convierte el tiempo en poesía. Es capaz de producir 86400 poemas al día, poemas que mutan cada segundo, cada minuto y cada hora. Pero antes de comenzar a analizarla es importante señalar que, el mismo año en que se exhibe por primera vez, Merhi publica también su primer poemario, titulado Poliverso andróctono. Y, además, exhibe otra obra plástica, homónima, en la colectiva Re-Readymade que, bajo la curaduría de Miguel Miguel, tuvo lugar en el Museo Alejandro Otero, como homenaje al 110 aniversario del nacimiento de Marcel Duchamp. La aparición simultánea del poemario y de las tres obras plásticas ese mismo año, obras que se presentan como extensión, como materialización del quehacer poético de Merhi, marcará el inicio, será el germen de una prolífica trayectoria artística.

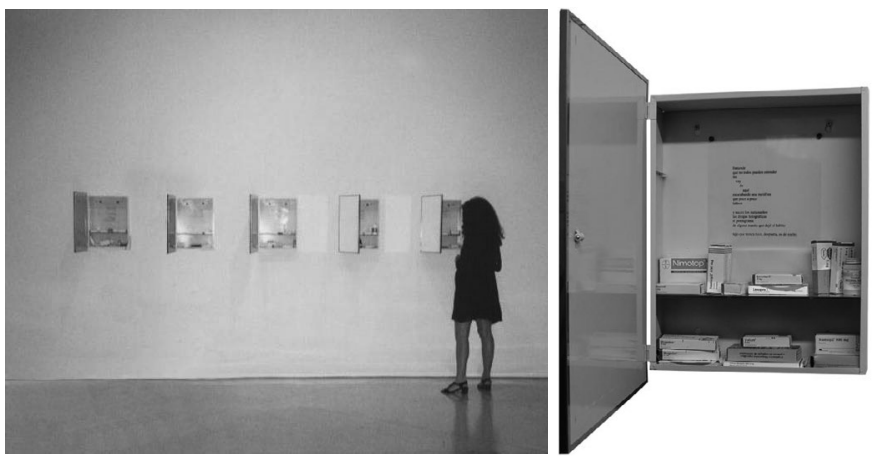

Poliverso andróctono (detalle de una de las piezas: Poliverso andróctono 5)

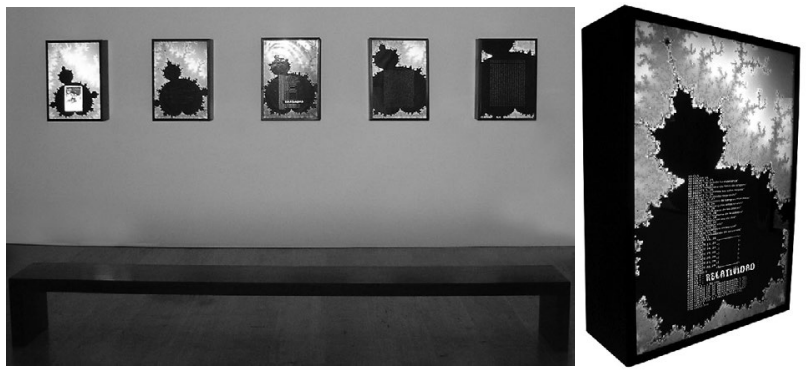

Abstractombola (detalle de una de las piezas de la serie: Abstractombola 3)

Debe aclararse que no es casual que estas obras aparezcan en el mismo momento; de ahí que sea necesario mencionarlas antes de comenzar a analizar El reloj poético. El hecho de que Merhi publique sus poemas en formato libro, del cual antes se han desprendido cinco que, como página 
impresa, se inscribieron dentro de un gabinete de baño, como es el caso en la serie Poliverso Andróctono, compuesta por cinco gabinetes con puerta de espejo, de $23,6^{\prime \prime} \times 16,5^{\prime \prime} \times 5,9^{\prime \prime}$ cada uno, que contienen en su interior, sobre los estantes y bajo el poema, diferentes antidepresivos, sedantes y barbitúricos; y que luego otros cinco — los últimos del poemario- se inscriban como proyección de luz dentro de las cinco cajas de luz que conforman la serie Abstractombola, de $35,4^{\prime \prime} \times 27,5^{\prime \prime} \times 7,8^{\prime \prime}$ cada una, en las que puede verse la imagen de un fractal de Mandelbrot dentro del cual se proyecta el poema; ya es señal de que hay un hilo conductor dando sentido a este aparecer simultáneo. Por ello puede decirse que no se trata de propuestas independientes, sino de obras intrínsecamente vinculadas entre sí, hasta el punto de que podría decirse que en ningún momento dejan de conformar o de ser parte del poemario, aunque sí se proponen como una manifestación de lo mismo en otra forma. $\mathrm{O}$ en otras palabras, como una materialización del poema que se da porque el lenguaje se extiende hasta adquirir forma, hasta convertirse en objeto, y así el objeto adquiere sentido, un nuevo sentido. El poema se convierte entonces en poema-objeto y de esa manera extiende su significado. Al respecto, afirma Merhi lo siguiente:

The physical object in my work is an extension of the poem, which expands the potential of words and extends the limits of language; while poetry becomes a prolongation of the object, providing an emotive and meaningful presence.

[El objeto físico en mi obra es una extensión del poema, que expande el potencial de las palabras y extiende los límites del lenguaje; mientras la poesía viene a ser la prolongación del objeto, al que provee de una emotiva y significativa presencia (Merhi, 2005, p. 20. La traducción es mía)].

Esta afirmación puede ser punto de partida para empezar a entender estas obras como el resultado de un ensamblaje que permite que comiencen a funcionar juntos el lenguaje y el objeto material. Pero parece sugerir también la necesidad de comprender este ensamblaje como un proceso que al parecer se va dando de manera natural, por necesidad, casi podría decirse que orgánicamente.

En los inicios de mi actividad artística - comenta Merhi en una entrevista publicada en el diario El Nacional, en $2005^{3}$ - me consideraba un escritor de poesía y asumí todas mis actividades en función de la acción poética. En un momento traté de extender los bordes del

3 Recuperado de http://cibernetic.com/press/elnacional/timeout.html 
ámbito literario y me fue necesario acceder al terreno de las artes visuales. Esto ocurrió por causas naturales y accidentales (AlfonzoSierra, 2005: s. p.).

Causas que parecen remitir a un impulso vital de la poesía que busca abrirse nuevos caminos para poder expresar, como diría Yolanda Pantin, «la música de su tiempo» ${ }^{4}$.

$Y$ en efecto, como hemos visto, las obras a las que nos estamos refiriendo se constituyen como manifestación del salto progresivo que da el poema - la poesía y el poeta - hacia un nuevo lugar de inscripción, hacia un nuevo formato, luego de haber transgredido, trascendido, las fronteras del formato tradicional: el libro. $Y$ no son solo esas fronteras las que son transgredidas por estas obras, sino también las que corresponden al ámbito literario y al artístico, y principalmente, como se verá más adelante, al poético y al tecnológico. Esto pone de manifiesto una de las características más resaltantes de Merhi: la creación a partir de la experimentación con/en los límites. Experiencia que se constituye como fundamento de su quehacer artístico/poético —el de un poeta que es también hackerdesde mucho antes de la aparición de estas obras a las que nos estamos refiriendo. Esta indagación comienza con la exploración lúdica del límite entre lenguajes naturales y lenguajes de programación, con los que estará familiarizado desde la infancia. A esto se refirió en una entrevista que le hizo el artista italiano Carlo Zanni en 2004:

When I started writing poetry, at the age of 10, I was already involved with programming languages. The connection I established between poetry and code took place in an unconscious state of mind that later on I became aware of. Since net@ari [considerada la primera obra

4 Esa expresión está tomada del texto con el que Yolanda Pantin participó en el V Coloquio Latinoamericano de Literatura «José Rafael Pocaterra», organizado por la Universidad Católica Andrés Bello (UCAB) y el Ateneo de Valencia (Venezuela) en 2000, y que fue publicado en las Actas correspondientes en 2002. Se titula «El poema que vendrá». Pantin comenta allí lo que fue su experiencia durante el Taller de Poesía que dictó en el Centro de Estudios Latinoamericanos Rómulo Gallegos (Celarg) de 1995 a 1996, en el cual participó Yucef Merhi, a quien la poeta venezolana nombra con la intención de reconocer el valor de su propuesta poética. La cita completa es la siguiente: «Yucef Merhi, 19 años. Para él la poesía no tiene ningún límite. Como muchos jóvenes de su edad, Merhi está totalmente familiarizado con los nuevos lenguajes uno de los cuales es el de las computadoras. Su apuesta —original o no- es mayor, porque es inconcebible, porque para nosotros es inconcebible. Merhi se expresa con un lenguaje híbrido donde todo es posible: poesía escrita, virtual, objetual. Es cierto que yo lo aupé y que fui entusiasta cómplice de sus locuras y experimentos, fascinada como estaba por las inéditas situaciones que el joven creaba y por sus virtuales universos. Porque, les decía yo a esos muchachos en el taller del Celarg que la poesía es un cuerpo vivo que avanza hacia algún lugar del cual no tenemos noticia y que en el camino expresa la música de su tiempo. Y le decía a Yucef Merhi que su trabajo colocaba a la poesía tradicional en las incomodidades de los límites, o en la angustia de los callejones sin salida, cuando las herramientas para saltar - que han sido siempre las de la imaginación y el sueño- se nos antojaban a nosotros los mayores, muy difíciles» (112. Énfasis mío). 
de Merhi, junto con bin@ri; ambas creadas cuando tenía 8 años de edad], produced in 1985, I've been exploring the bond between natural languages (English, Spanish, Hebrew, etc.) and programming languages (Basic, C, Java, Assembler, etc.). To me, code and poetry are very similar in structure and production. Even when they seem to be opposite, as poetry comes from grasping your emotions and code from digging into your brain, the way I write a poem or a piece of code is using the same tools, the same approach. When both languages are merged having poetry as a foundation, a new kind of interaction emerges.

[Cuando comencé a escribir poesía, a la edad de 10 años, yo ya estaba involucrado con los lenguajes de programación. La conexión que establecí entre poesía y código tuvo lugar en un estadio inconsciente de mi mente del que solo después fui capaz de tomar conciencia. Desdenet@ri [considerada la primera obra de Merhi, junto con bin@ri; ambas creadas cuando tenía 8 años de edad], producida en 1985, he estado explorando el límite entre lenguajes naturales (inglés, español, hebreo, etc.) y lenguajes de programación (Basic, C, Java, Assembler, etc.). Para mí, código y poesía son muy similares en cuanto a estructura y producción. Aun cuando parecen ser opuestos, pues la poesía nace de captar nuestras emociones y el código de excavar en nuestro cerebro, yo me valgo de las mismas herramientas, de la misma forma de aproximación para escribir un poema o un código. Cuando ambos lenguajes se fusionan teniendo como fundación la poesía, un nuevo tipo de interacción emerge (la traducción es mía)] $]^{5}$.

A partir de esto queda claro que Merhi parte de la convicción de que ambos lenguajes, a pesar de que parezcan opuestos, por ser uno racional y el otro emocional, pueden fusionarse. De hecho, en el propio comentario deja ver que cada lenguaje corresponde a una determinada facultad del cuerpo - materia - : la de pensar (racional) y la de sentir (emocional). Cabría entonces entender el cuerpo como continente formal dentro del cual coexisten ambos lenguajes - iensamblaje original?-. Abre con ello la posibilidad, la necesidad, podría decirse más bien, de repensar en otros términos la histórica confrontación entre cuerpo - materia-y espíritu, entre razón y poesía. Su propuesta: que la poesía funde una nueva interacción.

5 Recuperado de https://books.google.co.ve/books?id=jPHfAgAAQBAJ\&pg=PA90\&dq=Ca rlo+Zanni+Yucef+Merhi\&hl=es\&sa=X\&ved=0ahUKEwjY0Ni71Y_MAhWCcD4KHcs4C9AQ6A EIGzAA\#v=onepage\&q=Carlo\%20Zanni\%20Yucef\%20Merhi\&f=false 


\section{Tránsito hacia la desmaterialización}

A efectos de la presente investigación - y aun cuando es mucho lo que podría decirse acerca de estas obras iniciales ${ }^{6}$ con las que Merhi inaugura su trayectoria artístico poética-, lo que más interesa señalar, en relación con lo que será propuesto en este artículo, es que las dos series referidas -Poliverso andróctono y Abstractombola - parecen ofrecer al espectador -y ser en sí mismas - un registro del proceso de transición que experimenta la poesía durante el salto que la lleva de la página física, sobre la que se imprime primero con tinta el poema, hasta la página digital, en la que se presenta la escritura como proyección de luz sobre una pantalla. Se trata por tanto de una forma particular de registro progresivo $-y$ de representación - del salto que da la poesía - de Merhi en este caso, pero también la poesía en general- del ámbito físico, tradicional, al ámbito digital, propiciado como nuevo espacio por el desarrollo tecnológico. Esa misma transición queda registrada en la propia escritura de los poemas -alusión al lenguaje como fundamento del mundo, como espejo del mundo-, sobre todo en Abstractombola, pues en tres de los cinco poemas que la conforman el lenguaje natural y el lenguaje de programación convergen hasta que aparentemente este último termina por devorar al lenguaje natural ${ }^{7}$. De hecho, los dos poemas que cierran la serie resultan ilegibles: el primero, «Miguelángel», porque es el resultado de haber convertido en un poema visual la información del código fuente del primer virus informático que tuvo difusión mediática. En la imagen resultante lo único que puede leerse es una instrucción al principio, «begin 644 virus. zip», y otra al final, «end». Y en medio de ese principio y de ese fin, un amasijo caótico de signos que parece aludir al caos que precede a toda creación, a todo nuevo comienzo.

\footnotetext{
6 Un análisis más extenso de estas obras se encuentra en la tesis de grado titulada «Reconfigurando el sistema operativo: la poesía como código subversivo en Yucef Merhi», que presenté en la Universidad Simón Bolívar (Caracas, Venezuela), en octubre de 2013, para optar al título de magíster en Literatura Latinoamericana. Parte del análisis fue publicado en la revista Estudios del Departamento de Lengua y Literatura de la misma universidad. Recuperado de http://www.revistaestudios.Il.usb.ve/sites/default/files/Estudios_39/Daniela-Diaz.pdf

7 El primer poema de esta serie es una fotografía, alusión a la cualidad visual de la poesía, aspecto ampliamente trabajado por las vanguardias históricas, y también al salto que implicó la invención de este nuevo dispositivo de representación, como antecedente de la transición que nos ocupa, representada en los cuatro poemas siguientes: el primero, resultado de la "compresión» de dos poemas escritos en lenguaje natural; el segundo, en el que convergen ya el lenguaje natural y el lenguaje de programación Basic; el tercero, datos del código fuente de un virus informático esculpidos por el autor; $y$ el último, un poema cifrado en código hexadecimal.
} 


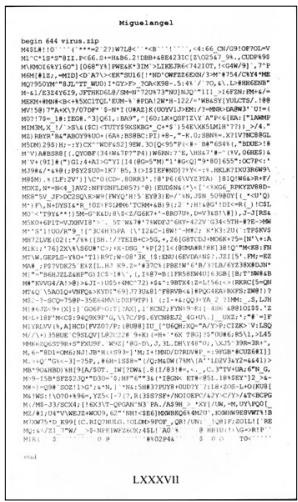

«Miguelangel». Poliverso andróctono (poemario)

Al respecto, explica Merhi lo siguiente:

La información [del código fuente del virus informático llamado «Miguelángel»], trabajada como si se estuvieran esculpiendo los datos [alusión a que surge una nueva (in)materialidad], adquirió el carácter de un poema visual donde las únicas instrucciones legibles son «begin 644 virus.zip» y «end». Entre el inicio y el fin se manifiesta el caos, un caos organizado que podría servir como analogía de la creación del universo (poético). El universo visto como virus, como aquello que todo lo altera y en todo se multiplica, y que para poder ser comprendido (decodificado) ha de tener un principio y un fin. (En página web oficial: www.cibernetic.com)

Fin y principio que en estas obras marcan, al coincidir, el cierre de un ciclo que deja al espectador al borde de un universo (poético) nuevo (entendido «como virus»; es decir, como aquello que se propaga y multiplica por contagio, alterando el orden preestablecido; y como aquello que revela un nuevo lugar de tránsito, un nuevo [in]organismo). Universo que se va abriendo, expandiendo, a medida que el desarrollo tecnológico construye con lenguaje de programación la (infra)estructura necesaria para sostener el espacio donde funcionará.

El nuevo orden, resultado del caos inicial, quedará representado en el último poema de la serie, ilegible también como el anterior, pero esta vez porque está encriptado, cifrado, incluso el título, en código hexadecimal. 


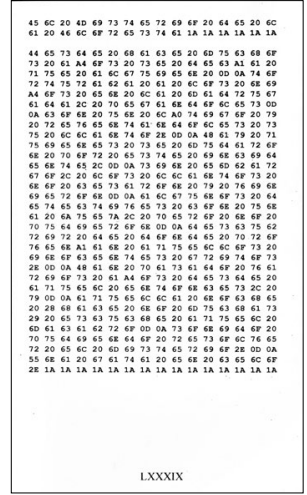

«Misterio de la floresta». Poliverso andróctono (poemario)

Del lenguaje natural tan solo quedan ahora, ante el espectador, algunas letras dispersas entremezcladas con números de los que ya no se diferencian por haber sido todos reducidos a la única condición de signo. Desaparece de esa forma todo contenido semántico posible. Los signos, ordenados en parejas sobre la página, forman filas que construyen una cuadrícula perfecta, una matriz - matrix - matemática, tecnológica, que alberga - o ha logrado capturar - en su interior un poema. Se completa así el proceso: la poesía - la voz del poeta en su cuerpo de lenguajeha sido trasegada simbólicamente, por medio de un proceso de síntesis propio del desarrollo de la tecnología, al interior de nuevos significantes que son los que servirán de medio en esta transición. El poema queda así escrito, sobre la página, no en lenguaje natural, sino en lenguaje de máquina. Es un poema, ahora, para la máquina. Un poema que ya no tiene lugar ni sentido en el espacio físico de la página y que responderá, de ahora en adelante, a un espacio y a un tiempo distintos.

\section{El reloj poético: la poesía como fundamento}

La tercera de las obras que aparece en este momento inicial de la trayectoria artística y poética de Merhi es justamente un reloj, artefacto que ha sido inventado por la física con la intención de medir y objetivar el transcurrir temporal de la naturaleza. En este caso, el tiempo que se marca parece corresponder al momento en el que la poesía comienza a expresarse a través de la máquina. En 1924, en su conferencia sobre el concepto de tiempo, Heidegger empezaba definiendo el reloj como «el modo en que el tiempo tiene oportunidad de mostrarse» (versión electrónica Uarcis, p. 6). Se refería en ese caso al modo en que se manifestaba el tiempo, a través de ese mecanismo, en términos físicos, objetivos, como una medición del «cuándo», del «cuánto». En el caso de $E I$ reloj poético de Merhi, intentaremos mostrar cómo la intervención de la 
poesía complejiza, enriquece y aporta, o recobra, otros sentidos de esa manifestación.

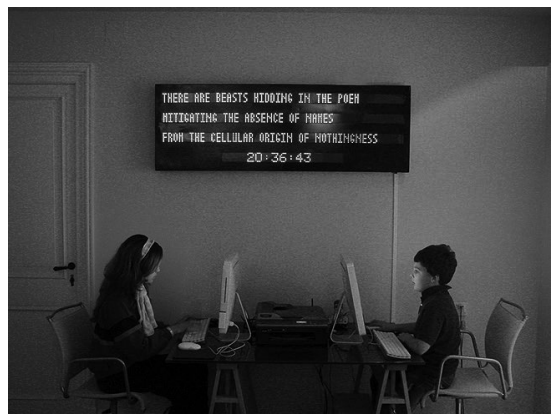

El reloj poético (1997). Fuente: www.cibernetic.com

Como ya se dijo, esta obra fue exhibida por primera vez junto a Abstractombola en el III Salón Pirelli (1997) —donde obtuvo mención de honor-, pero fue concebida como concepto, como fórmula, según comenta el artista, años antes. Sobre esto cuenta Merhi lo siguiente:

La creación de esta obra tuvo lugar mientras analizaba unos ejercicios de lógica proposicional como parte de mi preparación para las pruebas académicas ${ }^{8}$. Tenía en aquel entonces 17 años (1994). Poco tiempo después contacté a una empresa que se especializaba en la construcción de pantallas digitales. Les ofrecí diseñar su página web y programar la red intranet a cambio de asesoría en el diseño y producción del aparato. Es uno de los mejores trueques que he hecho en mi vida. De esa manera, lo que inicialmente fueron unas hojas con fórmulas y axiomas terminó convirtiéndose en máquina y luego en software?

Este comentario aporta los datos precisos acerca de cuándo «tuvo lugar» la creación de la obra, bajo qué circunstancias, y cómo fue el proceso que permitió el tránsito desde su inscripción como fórmula o axioma en una hoja de papel hasta su materialización a partir de su conversión en máquina analógica. Primer estadio al que seguirá una nueva transformación que implica el paso de máquina a software -aparecen entonces $\mathrm{El}$ reloj poético 2.0 (2000) y El reloj poético 3.0 (2008) - y que, comenta Mer$\mathrm{hi}^{10}$, sigue los lineamientos de Nicholas Negroponte sobre la conversión de átomos a bits; cambio «irrevocable e imparable», según afirma este

8 Yucef Merhi estudió Filosofía en la Universidad Central de Venezuela.

9 Fuente: entrevista privada con la autora del 24 de noviembre de 2013.

10 En comentario sobre la obra disponible en la página oficial del artista: http://cibernetic. com/indexart.html 
autor en su conocido libro Ser digital (1995), que consiste en el proceso de digitalización progresiva de la realidad, una vez ha sido reducida a información.

Encontramos así de nuevo, representado en la obra de Merhi, ahora a partir de las sucesivas actualizaciones de su formato de exhibición, el registro de esa mutación que caracteriza nuestro tiempo, signada por el salto de lo matérico a lo digital y considerada también por Pierre Lévy, en su libro ¿Qué es lo virtual? (1995), como un proceso inevitable de virtualización de la realidad. «La virtualización - afirma Lévy al respecto en el libro referido - constituye la esencia o el punto preciso de la mutación en curso. [...] Se presenta como el movimiento del «convertirse en otro» - o heterogénesis de lo humano-» (1995, p. 7). Ahora bien, cabría preguntarse: ¿en qué nos estamos convirtiendo?

Según el postulado de Negroponte, podría entenderse que progresivamente nos estamos convirtiendo en bits.

Un bit - aclara este autor - no tiene color, tamaño ni peso y viaja a la velocidad de la luz. Es el elemento más pequeño en el ADN de la información. Es un estado de ser: activo o inactivo, verdadero o falso, arriba o abajo, dentro o fuera, negro o blanco (versión digital: s. p.).

Un estado de ser, entonces, que ha perdido toda cualidad sensorial y que al parecer no acepta matices, que solo puede ser una cosa o su contrario. $Y$ en relación con esto valdría la pena tener en cuenta también lo que sobre los bits advierte Lyotard:

son - dice- unidades de información concebidas por la ingeniería de la computadora y definibles en todos los niveles de lenguaje: lexical, sintáctico, retórico y los demás. Se reúnen en sistemas de acuerdo con un conjunto de posibilidades (un «menú») bajo el control de un programador (1998, p. 43).

A partir de estas dos definiciones no parece equivocado decir que nos estamos convirtiendo en unidades de información que se constituyen como un estado de ser binario, clasificable y programable. Pero si esto es así, ¿qué pasa con la poesía? ¿Qué pasa con todo lo que no cabe dentro de una concepción del mundo y del ser en términos binarios?

En el comentario de Merhi acerca de cuándo y cómo crea su obra encontramos también, de nuevo, una alusión significativa al hecho de que el lenguaje es siempre fundamento, punto de partida para la creación/ construcción/materialización de la realidad (del mundo) -El reloj poético es antes que nada axioma, fórmula inscrita sobre una hoja de papel-; sea que se trate de lenguaje natural o de lenguaje matemático... o de lenguaje de programación. Cada uno, por supuesto, con sus particulares 
características, con su singular naturaleza, que es la que determinará sus posibilidades o sus potencialidades.

Se ha mostrado ya, al menos en parte, cómo Merhi en Abstractombola — quizá actualizando el espíritu altazoriano de Huidobro- representa la transición que nos ocupa a partir de la convergencia entre lenguaje natural y lenguaje de programación; una convergencia que más parece un proceso de colonización del código sobre el lenguaje natural. En este sentido es importante señalar también que los poemas que forman parte de la serie Poliverso andróctono, que son en el poemario los que anteceden a los de Abstractombola, «evocan — según puede leerse en el catálogo de la exposición Re-Readymade- el agotamiento de la psique asociada al solipsismo del lenguaje analítico» (1997, p. 30), con el que se ha pretendido, sobre todo a partir del auge del formalismo lógico y matemático que tiene lugar a mediados del siglo XIX, como señala Lyotard en Lo inhumano (1998, pp. 76-83), reducir a análisis lógicos el potencial sensible y artístico del pensamiento humano, fuente de todo proceso creativo que va agotándose a medida que va siendo transformada en información veraz, útil y verificable.

En el último gabinete de la serie Poliverso andróctono puede leerse:

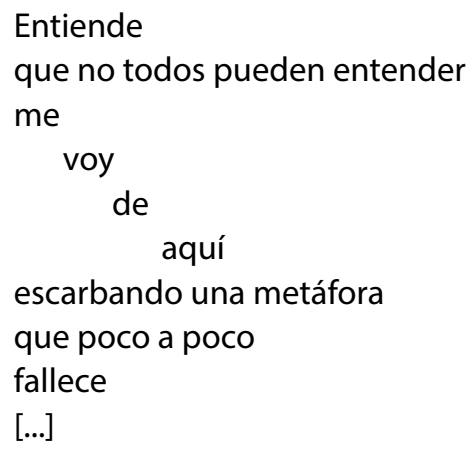

A partir de esto resulta mucho más significativo el hecho de que Merhi especifique, en su comentario sobre El reloj poético, que la creación de esta obra «tuvo lugar mientras analizaba unos ejercicios de lógica proposicional», método que consiste, como se sabe, en aplicar el principio de razón suficiente a fin de determinar la veracidad o la falsedad de cualquier proposición. Principio de razón que marcó el camino del desarrollo tecnológico al que la especie humana ha tenido constantemente que adaptarse.

Que el discurso «cognitivo» —advierte Lyotard en el libro referidohaya conquistado la hegemonía sobre los otros géneros, que en el lenguaje corriente el aspecto pragmático e interrelacional pase al primer 
plano, mientras que «lo poético» parece merecer cada vez menos atención [...] Son los signos de que se introduce un nuevo uso del lenguaje cuyo desafío es conocer los objetos con la mayor exactitud posible y alcanzar respecto de ellos, entre los locutores corrientes, un consenso tan amplio como el que supuestamente reina en la comunidad científica (p. 76).

Signos, entonces, de que el lenguaje está siendo utilizado como instrumento científico para establecer acerca de la realidad verdades o conceptos generales, por consenso; signos de que está siendo sometido a esa reducción que lo obliga a la exactitud, a la univocidad, con la intención de «dotar al espíritu del conocimiento más exacto de la realidad y controlar en la mayor medida posible su transformación» (p. 78). En ese caso - continúa Lyotard — , «la verdadera tarea del filósofo [consistiría] en ayudar a la ciencia a sustraerse a las inconsistencias que entrañan las lenguas naturales, mediante la construcción de una lengua simbólica, pura y unívoca» (p. 78). Pero son esas «inconsistencias que entrañan las lenguas naturales» aquello que constituye justamente su potencial creativo, generativo, regenerativo. Son esas inconsistencias: las ambigüedades, las contradicciones, las ocurrencias, lo inusitado, en fin, lo incontable, aquello que es propio del lenguaje entendido más bien como «campo de percepción capaz de "tener sentido" por sí mismo independientemente de toda intención de significar». Es a este campo al que pertenecen la poesía y el arte, la literatura y todos aquellos géneros del discurso «asociados al principio de imaginación productora» (p. 78). Formas heterogéneas que, lejos de pretender controlar o establecer reglas a lo dicho, más bien se abren a recibir las ocurrencias, a lo que pueda acontecer a partir del discurrir libre del lenguaje, entendido entonces como medio receptivo, pasible y creativo. Géneros sobre los que se ha impuesto, como queda expresado en los poemas de Merhi —expresión de la música de nuestro tiempo—, no solo el discurso lógico, científico-matemático, sino también, ahora, el lenguaje de programación. ¿Cómo entonces invertir la ecuación?

Según Lyotard, esta escisión entre lo racional y lo que por oposición es considerado irracional afecta esencialmente la naturaleza del lenguaje porque impone una división que lo desnaturaliza. Lo mismo, podría decirse, pasa con el tiempo si su comprensión se reduce únicamente a la forma en que se manifiesta a través de un reloj.

Un reloj - explica Heidegger en la conferencia referida - es un sistema físico, en el cual se repite constantemente la misma secuencia temporal, bajo el supuesto de que este sistema físico no está sujeto a alteración por una influencia exterior. La repetición es cíclica. Cada periodo tiene la misma duración temporal. El reloj da una duración 
idéntica que se repite constantemente, a la que siempre se puede volver a recurrir. La división de esta extensión durable es arbitraria. El reloj mide el tiempo en tanto que la extensión de la duración de un acontecer es comparada con secuencias idénticas del reloj y, a partir de esto, es determinada numéricamente en su Cuánto (Soviel) (versión electrónica Uarcis, p. 7).

Esta explicación muestra cómo el reloj, en tanto mecanismo que mide el tiempo, opera reduciendo «la extensión de la duración de un acontecer» a un "Cuánto», es decir, a una cantidad numérica que la determina -operación equivalente a la de reducir la realidad a conceptos generales-. El acontecimiento queda inscrito así en un tipo de duración que es cuantificable porque ha sido dividida en segmentos homogéneos, que a su vez sirven como modo de registro del tiempo en el espacio, al asignarle a la duración una extensión. A esto apunta Lyotard cuando afirma que «El calendario y el reloj constituyen redes de tiempo objetivo» (p. 65), pues determinan los momentos, los acontecimientos, los espacializan, los objetivan.

Es esta máquina, destinada en principio a medir el tiempo, siempre en presente, siempre igual, la que Yucef Merhi intervendrá con poesía. De nuevo, entonces, nos encontramos ante el resultado de un ensamblaje entre lenguaje y objeto. La diferencia es que en este caso el objeto es una máquina y es a través de ella que la poesía - cuya naturaleza, como afirma Merhi en muchas ocasiones ${ }^{11}$, es subversiva- comenzará a funcionar, adquirirá dinamismo y será, como el tiempo, movimiento y cambio incesante. El poema entonces será, ahora, poema en constante mutación. Y la máquina, antes objetiva, adquirirá subjetividad, voz. Se propone, por tanto, esta obra como un modo singular de programar la máquina partiendo de la poesía como fundamento.

11 Esto lo afirmará en la entrevista publicada por El Nacional en 2005, a la que ya nos hemos referido, y con mayor énfasis y detalle en el texto que escribe ese mismo año para De Apple Reader N. 3 , titulado The Subversive Circle of Poetry, y que se constituye como una suerte de manifiesto de su poética. En ese texto dice Merhi: «Poetry is subversive by nature. This quality was clearly present in the works of Dada, The Surrealists, OULIPO, and Fluxus, among others groundbreaking groups. As a consequence, digital art and new media come from a legacy of poetic rebellion. Thus, in order for this new art structures to be effective they have to perpetuate the subversive condition of poetry» [La poesía es subversiva por naturaleza. Esta cualidad estuvo claramente presente en las obras del dadaísmo, en los surrealistas, OULIPO y Fluxus, entre otros grupos vanguardistas. De ello se desprende que tanto el arte digital como el de los nuevos medios surgen a partir de un legado de rebelión poética. Por consiguiente, a fin de que sea efectiva la incorporación de estas nuevas formas de arte, será necesario que ellas perpetúen esa condición subversiva de la poesía»] (p. 21. La traducción es mía). 


\section{Recobrar el tiempo a través del reloj}

Cuando por primera vez fue exhibido El reloj poético, en 1997, este estaba conformado por una pantalla LED, de $18^{\prime \prime} \times 55,5^{\prime \prime} \times 10^{\prime \prime}$, fabricada por el artista y conectada a través de circuitos electrónicos a una computadora que contenía la base de datos con 144 versos escritos por él.

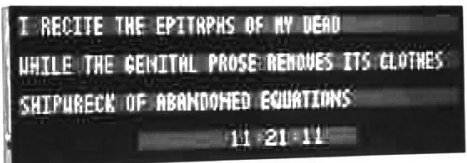

El reloj poético (1997). Fuente: www.cibernetic.com

El funcionamiento de este particular reloj analógico dependía de un software programado en Flash. La pantalla estaba dividida en cuatro franjas. En la primera aparecía un verso nuevo cada vez que cambiaba la hora; en la segunda, también aparecía un nuevo verso pero cada vez que cambiaban los minutos; y en la tercera, cada vez que cambiaban los segundos. En la cuarta franja aparecía la hora dispuesta según el formato HH:MM:SS. De esta manera, se presentaba El reloj poético como una máquina capaz de generar 86400 poemas al día, uno por cada segundo, lo que significa que no solo era capaz de convertir el tiempo en poesía, sino que además lo transformaba en una constante recitación.

Estas cuatro franjas se mantendrán en todas las versiones posteriores: los números que marcan el transcurrir del tiempo y los versos que transmutan cada segmento en poesía. Es así como Merhi hará visible que, paralela a la duración a la que Heidegger se refería en el fragmento citado y que corresponde al modo en que el reloj mide el tiempo, transcurre otra que es de distinta naturaleza, más afín a la duración a la que se refiere Bergson. La duración, para Bergson, según comenta David Lapoujade en su libro Potencias del tiempo. Versiones de Bergson (2011), es «el elemento puramente espiritual del tiempo, su propia sustancia» (p. 9). Ya no es cantidad sino cualidad. Ya no es medición sino emoción, entendida esta como «el efecto que produce el fluir del tiempo en la sensibilidad» (p.7). Y en ese sentido remite al individuo, pues para que haya emoción debe haber quien la experimente; y también remite, por supuesto, al cuerpo del individuo, por ser este el medio - material - percipiente a través del cual es posible la experiencia. Por ello Heidegger, a partir de su reflexión sobre el tiempo, traza un camino que lo lleva a sugerir que la pregunta que más se acerca a este no es «¿Qué es el tiempo?», sino «¿Quién es el tiempo?». O, más específicamente, «¿Soy yo mi tiempo?». Lapoujade, por su parte, en su reflexión sobre la filosofía de Bergson también deja ver que solo es posible acercarse a la comprensión del tiempo si este se piensa a partir de un «quien» y no de un «que»: 
Es la propia duración - dice- la que, en nosotros, es emoción. Inversamente, es solo a través de las emociones que somos seres que duran o más bien que dejamos de considerarnos como seres para devenir duraciones, como un sonido existe y dura por su vibración, y por nada más. En lo profundo, ya no somos «seres», sino vibraciones, efectos de resonancia, «tonalidades» de alturas diferentes (p. 7).

Esta vibración, esta resonancia, pertenece a un orden de naturaleza distinta a la del número, a la de lo medible o cuantificable. Es una vibración que es propia, más bien, del ámbito de lo sensible: justamente ese que pierde todo aquello que se convierte en bit; justamente ese que corresponde a la parte del lenguaje que está cargada de «inconsistencias» y que no es razón sino emoción. Programar entonces la máquina incorporando poesía en su funcionamiento, con la intención de que sea capaz de pronunciarla a través de su mecanismo, constituye un acto subversivo, pues a través de la poesía el artista/poeta fuerza a la máquina a poner de manifiesto esa otra duración que, por más que pretenda ser negada, porque escapa a los parámetros de lo que se supone es verdadero, existe, transcurre, es parte del ser, fundamento y potencia de la vida.

$$
\begin{aligned}
& \text { LEVITAN LAS PALABRAS EN NUESTRA AUSENCIA } \\
& \text { ENTRE ESCOMBROS DE SOMBRAS EXTRAVIADAS } \\
& \text { CONJUGANDO LOS VERBOS DE UNA LENGUA OXIDADA } \\
& 11: 25: 05 \text { PM } \\
& \text { LEVITAN LAS PALABRAS EN NUESTRA AUSENCIA } \\
& \text { RESOLVIENDO DELIRIOS ALGEBRAICOS } \\
& \text { MIENTRAS ARDE LA FÉRTIL ANSIEDAD }
\end{aligned}
$$
LEVITAN LAS PALABRAS EN NUESTRA AUSENCIA RESOLVIENDO DELIRIOS ALGEBRAICOS MIENTRAS ARDE LA FÉRTIL ANSIEDAD

$11: 26: 34$ PM

LEVITAN LAS PALABRAS EN NUESTRA AUSENCIA MIENTRAS LA PROSA ENTIERRA AL POEMA RECIÉN NACIDO FERMENTANDO LA NEGACIÓN MÁS EBRIA DEL HOMBRE $11: 28: 38 \mathrm{PM}$

\author{
LEVITAN LAS PALABRAS EN NUESTRA AUSENCIA \\ EN MI SENSUALIDAD DE POEMAS AMARILLOS \\ LAMIENDO LA PLANTA DE MI SER
}

$11: 30: 45 \mathrm{PM}^{12}$ 
Esta obra en su versión original fue exhibida, entre 1997 y 2000 - que es cuando muta a software - , también en México, Brasil y Estados Unidos, y es interesante tomar en cuenta el hecho de que se trata de un reloj que, al momento de exponerse, se sincroniza con el tiempo de cada lugar y, así conectado, comienza a transmutarlo en poesía. Se trata entonces de lo que podríamos denominar una máquina híbrida, porque, por una parte, cumple la función propia de la técnica, es decir, la de patentizar un transcurrir -el del ciclo natural del día y de la noche- que para poder establecerse como orden y medida eficiente, para poder maquinizarse, tuvo que ser dividido en segmentos homogéneos según los cuales se determinaron las horas, los minutos y los segundos; y porque, al mismo tiempo, se trata de una máquina que invita al espectador a detenerse ante ese incesante paso de número sin significado al ofrecerle la posibilidad de leer en forma de verso cada hora, cada minuto, cada segundo. Puede entonces así, quien esté ante este reloj, experimentar el tiempo como una sucesión de versos cuyo sentido permite escapar al límite que como simple medida - cuantificación - impone el número, la proporción, el segmento. Escapar, por tener la posibilidad de tomar conciencia de ello, de aquello que ha sido negado, ahora que la propia máquina permite constatarlo, lo revela. Ha sido en ese sentido forzada por el artista a mostrar lo velado. Ha sido subvertida por la poesía. Con su intervención, Merhi ha abierto una rendija por la cual lo que ha permanecido al margen, aquello que el desarrollo tecnocientífico ha pretendido descartar, logra ser expresado, logra expresarse.

El tiempo se convierte así en un testimonio poético —el del poeta, el de «lo poético»- gracias a la voz que le brindan los versos, y ello permite -y es quizá esto lo más interesante- que el espectador, a partir de esa experiencia, recobre la totalidad temporal fragmentada por la técnica, la continuidad de su transcurrir, pues se le ofrece la posibilidad de entrelazar y de reentretejer entre sí los intervalos, gracias a que la lectura de los tres versos, que convierte además esa voz en su propia voz, produce, como señala el mismo Merhi, «un poema articulado y coherente», un poema que es un todo cada segundo y que está vivo porque está en movimiento; $y$, por eso mismo, revela no solo su sentido, sino también la imposibilidad de determinarlo, porque no cesa de ser siempre otro, siempre un «ahora» inatrapable, inasible. Escapa así el tiempo al segmento al haber recobrado la posibilidad de expresarse a través de la poesía. Y escapa el lenguaje de la reducción que le impone la lógica del número al haber recobrado su potencial capacidad de decir. Lo dicho expresa la música de nuestro tiempo a través de ese otro ritmo marcado por la cadencia de las palabras. Cada hora, así, da lugar a un mismo poema que muta 3600 veces dentro de ella 
antes de convertirse en otro, que mutará a su vez a partir de sí mismo 3600 veces más hasta ser otro de nuevo.

«Continuo manar — dice Paz en El arco y la lira (1994)—, perpetuo ir más allá, el tiempo es permanente trascenderse» (p. 57). Esto revela también del tiempo su innata condición cíclica, su límite paradójicamente ilimitado, su eternizada repetición que sin embargo es siempre diferencia. El reloj poético producirá 86400 poemas al día que volverán a repetirse al día siguiente, y así sucesivamente. Pero nunca será el mismo poema, porque siempre resonará en otro espectador. Con ello, como diría Lyotard, esta máquina revela del tiempo «el fin sin fin que supone» (1998, p. 18), particularidad que deja al descubierto su vínculo indisoluble con lo atemporal, pero no entendido como concepto opuesto al tiempo, sino en el sentido de aquello que es "continuo manar», discurrir, fluir, infinita multiplicidad en incesante movimiento que es parte indisoluble del tiempo y que constituye el insondable fondo de nuestra memoria. Eternidad que es siempre y nunca el estar, el ser, la vida, la muerte.

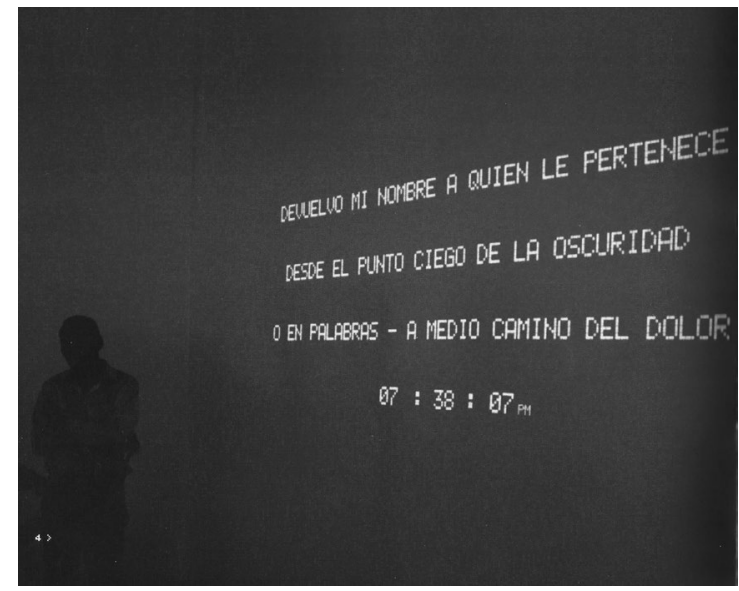

DEVUELVO MI NOMBRE A QUIEN LE PERTENECE DESDE EL PUNTO CIEGO DE LA OSCURIDAD O EN PALABRAS - A MEDIO CAMINO DEL DOLOR $07: 38: 07$ PM

Estamos entonces ante una máquina que invita a percibir, a experimentar otras dimensiones, otras manifestaciones de lo temporal al permitir, por otorgarle voz y significado, que se pronuncien íntimamente, de otra manera, las distintas velocidades que lo conforman: la hora de mirada lenta, el constante latido del minuto y el segundo de paso acelerado y fugaz. Y así también las rescata, al permitir que cada segmento de duración 
sea de nuevo palabra, ese otro ritmo que es más bien resonancia imantada que nos salva del número y nos devuelve al espacio vivo, continuo, abierto, pasible y creativo del lenguaje. Ante este singular reloj, cada espectador podrá tener, por tanto, una experiencia del tiempo que siempre será propia e irrepetible, a la vez que común, por ser inseparable del espacio en que se encuentra - nos encontramos- junto con los otros.

LEVITAN LAS PALABRAS EN NUESTRA AUSENCIA FILTRANDO LA MUERTE EN ESPEJOS DE ARENA

EN LA ESQUIRLA DE OTRO TIEMPO

$11: 29: 06$ PM 


\section{REFERENCIAS BIBLIOGRÁFICAS}

\section{BIBLIOGRAFÍA DIRECTA}

Merhi, Y. (s. f.). Sitio web oficial. Recuperado de http://www.cibernetic.com Tropykos.

(1997). Poliverso andróctono. Caracas: Fondo Editorial

(1997). Poliverso andróctono. Recuperado de http:// www.cibernetic.com/art/project/poliverso-androctono/index.html

(1997). Abstractombola. Recuperado de http://www. cibernetic.com/art/project/abstractombola/index.html

(1997). El reloj poético. Recuperado de http://www.cibernetic.com/art/project/poetic-clock/index.html

(2000). El reloj poético 2.0. Recuperado de http://www. cibernetic.com/art/project/poetic-clock2/index.html

Appel.

(2005). The Subversive Circle of Poetry. Ámsterdam: De

(2008). El reloj poético 3.0. Recuperado de http://www. cibernetic.com/art/project/poetic-clock3/index.html. Video recuperado de http://wizart.org/reloj_poetico.mp4

\section{BIBLIOGRAFÍA SOBRE EL ARTISTA}

Alfonzo-Sierra, E. (1 de marzo de 2005). Yucef Merhi crea un paisaje que muta en tiempo real. El Nacional. Recuperado de http://cibernetic.com/ press/elnacional/timeout.html.

Zanni, C. (31 de marzo de 2004). Interview with Yucef Merhi. Magazine. Recuperado de https://books.google.co.ve/books?id=jPHfAgAAQBAJ\& $\mathrm{pg}=$ PA90\&dq $=$ Carlo + Zanni + Yucef + Merhi\&hl $=e s \& s a=X \& v e d=0$ ahUKEw jY0Ni71Y_MAhWCcD4KHcs4C9AQ6AEIGzAA\#v=onepage\&q=Carlo\%20 Zanni\%20Yucef\%20Merhi\&f=false.

\section{CATÁLOGOS}

Re-Readymade (Colectiva). Caracas: Museo Alejandro Otero. Del 10 de agosto al 6 de octubre de 1997. Curaduría de Miguel Miguel.

\section{BIBLIOGRAFÍA GENERAL}

Deleuze, G. (1987). El bergsonismo. Madrid: Cátedra. Recuperado de https://monoskop.org/images/e/e9/Deleuze_Gilles_El_bergsonismo.pdf 
Díaz Larralde, D. (2013). Reconfigurando el sistema operativo: la poesía como código subversivo en Yucef Merhi (tesis de maestría en Literatura Latinoamericana). Universidad Simón Bolívar, Caracas.

(2012). Inseminar un poema en la matriz tecnológica.

De la poesía a la acción poética en Yucef Merhi. Revista Estudios, 20(39), pp. 65-96. Recuperado de http://www.revistaestudios.ll.usb.ve/sites/default/ files/Estudios_39/Daniela-Diaz.pdf

Heidegger, M. (1999). El concepto de tiempo (conferencia ante la Sociedad Teológica de Marburgo, julio de 1924). Recuperado de http:// v2.reflexionesmarginales.com/index.php/num7-documentos-blog/94heidegger-el-concepto-de-tiempo-pdf

Lapoujade, D. (2011). Potencias del tiempo. Versiones de Bergson. Buenos Aires: Cactus.

Lévy, P. [1995] (1998). ¿Qué es lo virtual? Barcelona: Ediciones Paidós. Recuperado de http://www.hechohistorico.com.ar/Archivos/Taller/Levy\%20 Pierre\%20-\%20Que\%20Es\%20Lo\%20Virtual.PDF.

Lyotard, J. F. [1988] (1998) Lo inhumano. Buenos Aires: Ediciones Manantial.

Negroponte, N. (1995). Ser digital. Barcelona: Ediciones B. Recuperado de http://users.dcc.uchile.cl/ cgutierr/cursos/INV/serDigital.pdf

Pantin, Y. (1999). El poema que vendrá. Caribe: Revista de Cultura y Literatura, 2(2), pp. 76-82.

Paz, O. [1956] (1994). El arco y la lira. Santa Fe de Bogotá: Fondo de Cultura Económica.

Recibido: abril de 2016

Aceptado: julio de 2016 